\title{
Backgrounding the Discussion Section of Medical Research Articles
}

\author{
Yasir Bdaiwi Jasim Al-Shujairi' ${ }^{1}$, Farah Abdul-Jabbar Al-Manaseer² \\ ${ }^{1}$ English Department, College of Education, Al-Zahraa University for Women, Karbala, Iraq \\ ${ }^{2}$ Department of English Language and Literature, College of Arts, Mustansiriyah University, Baghdad, Iraq \\ Email: yassir.bdaiwi@alzahraa.edu.iq,dr.farah_fa78@uomustansiriyah.edu.iq
}

How to cite this paper: Al-Shujairi, Y. B. J., \& Al-Manaseer, F. A.-J. (2022). Backgrounding the Discussion Section of Medical Research Articles. Open Journal of Modern Linguistics, 12, 71-88.

https://doi.org/10.4236/ojml.2022.121008

Received: January 27, 2022

Accepted: February 19, 2022

Published: February 22, 2022

Copyright $\odot 2022$ by author(s) and Scientific Research Publishing Inc. This work is licensed under the Creative Commons Attribution International License (CC BY 4.0).

http://creativecommons.org/licenses/by/4.0/

\begin{abstract}
The discussion section is considered as a crucial part in the writing process of a research article (RA). Research writers find it difficult to write an effective discussion for their results and this could be due to the unawareness of the various move functions that shape this section. A rhetorical move is a sentence or group of sentences that serves a communicative function. This paper focuses on move Background information, its linguistic devices such as verb, tense, and self-reference and lexical bundles (LBs) including 3- to 5-word bundles that are used to construct this communicative move. The corpus of the study includes a total of 50 medical RAs discussion section which were selected from five prestigious journals in the field. The corpus was analysed in terms of the occurrence of move Background information, the linguistic devices associated with this move and the LBs that initiate it. The analysis of the move and the linguistic realizations was done manually and the identification of LBs was done using AntConc3.5.7w computer program. The findings revealed that $34(64 \%)$ of the corpus included move Background information. This move was mainly employed to describe methodological aspects and restate the research purpose. These functions were characterized by the use of procedural verbs, first-person plural pronouns and simple past tense. Moreover, several 3 - 5 words LBs (e.g., we tested the hypothesis, this study was based on) were found to initiate move Background information. Further studies are needed to examine other obligatory and optional moves such as Explaining research findings and Indicating research limitations.
\end{abstract}

\section{Keywords}

Discussion Section, Move Background Information, Linguistic Devices, Lexical Bundles

\section{Introduction}

The research article (RA) has become the gateway for the exchange of knowledge 
among researchers from different discourse communities. This growth in published RAs along with Swales' (1990) discussion of communicative moves in research has turned RA into a high-status genre to be examined in various studies concerned with academic writing. An important and most crucial section of RAs is the discussion section as stated by many scholars (e.g., Amnuai, 2017; Basturkmen, 2012; Dujsik, 2015; Moyetta, 2016). It has been noted that the discussion section is essential in RAs (Basturkmen, 2012) and one of the most demanding sections for researchers, especially for novice writers (Amnuai, 2017).

The discussion section of an RA has several functions. Moyetta (2016) asserts that the primary purpose of the discussion section is to state the results and introduce the work of others "for confirmation, comparison or contradistinction" (Swales \& Feak, 2004: p. 235). On the other hand, Basturkmen (2012) has argued that this section allows researchers to make claims on the integration of the results and state the contributions to disciplinary knowledge. Similarly, Sheldon (2013) states that the most substantial claims of a study would be made in this section. Nonetheless, Dujsik (2015) has noted that the discussion section is focused on presenting and interpreting findings. Therefore, this section is not limited to restating findings from the research but also explaining them by providing reasons and examples that could support the arguments. Besides comparing the findings with the literature and stating claims, this section would sometimes include limitations, recommendations, and implication of the study. These various functions are called communicative (or rhetorical) moves and steps.

A rhetorical move is generally viewed as a function of a specific segment in a text (Yang \& Allison, 2003). The move can be a sentence, group of sentences or a paragraph that serves one or multiple communicative functions in a text. On the other hand, a step is a precise rhetorical mean that is employed to reveal and address the multiple functions of a move (Yang \& Allison, 2003). Thus, a step is at a lower level than a move, which functions as an "elaborator" of a move. The focus of this study, however, is on one particular rhetorical move, which is Background information.

Move Background information has been found and defined by some scholars in the field of ESP. This move can be employed to introduce the readers for the discussion of findings that follows (Amnuai \& Wannaruk, 2012). In this, it could include restating statements such as research questions, research objectives, theoretical background and methodological aspects. According to Amnuai (2017) and Liu and Buckingham (2018), research authors in the field of accounting and dentistry prefer to begin their discussion by giving an introductory information. In addition, move Background information may involve highlighting research gaps, proposing claims and stating deductions (Jin, 2018). On the other hand, Liu and Buckingham (2018) stated that move Background information mainly provides research objectives. Nwogu (1997) who examined medical corpus, noted that Providing background information allows writers to contextualize the study and "indicates that the research derives from a lively tradition of established works in the field" (p. 126). 
Throughout the literature, this move was named differently by different researchers. For instance, it has been named as move Information (Peacock, 2002), Give background information (Hopkins \& Dudley-Evans, 1988), and Provide background information (Swales, 1990). The present study considered the name Background information as named by Dudley-Evans (1994) in his framework who followed the framework from Swales (1990), which was described by Peacock (2002) as "the complete description of moves in the discussion section of research articles" (p. 224). Despite the various proposed names, move Background information serves the same function which is providing aspects related to the purpose of research, the theoretical framework, method, and procedure.

There are two reasons behind examining move Background information. First, past studies on move analysis examined the structure of RAs discussion section as a whole but did not conduct a deep investigation of the communicative moves individually. The current research seeks to focus on only move Background information which has been identified as either conventional or optional in recent studies (e.g., Arsyad et al., 2020a; Al-Shujairi et al., 2019; Amnuai, 2017; Liu \& Buckingham, 2018). Second, move analysis of the discussion section was mostly done in terms of frequency occurrences and percentages (e.g., Jin, 2018; Moyetta, 2016). Little attention was given to examine the linguistic characteristics of the identified rhetorical moves in this section. This paper, therefore, aims to explore the linguistics devices that realize move Background information and the lexical bundles that are associated with it.

\section{Research Questions}

1) What is the frequency occurrence of move Background information in the discussion section of medical RAs?

2) Through which linguistic devices does the communicative function of move Background information realized?

3) What sentence initial lexical bundles are associated with move Background information in the discussion section of medical RAs?

\section{Recent Studies Concerning Move Background Information}

A considerable effort was made recently to examine the rhetorical moves of RAs discussion section. Many studies have investigated the structure and organization of this section. Some of these studies examined one discipline (e.g., Basturkmen, 2012; Dobakhti, 2016; Arsyad et al., 2020b; Jin, 2018) while others investigated the disciplinary variations (e.g., Al-Shujairi et al., 2019; Liu \& Buckingham, 2018; Sadeghi \& Alinasab, 2020). Despite the number of studies that researched the rhetorical moves in the discussion section of RAs, they lack the deep analysis of what characterize these moves and what linguistic devices employed to realize the function of the discussion moves.

Nodoushan (2012) analysed the rhetorical moves in the discussion of 46 RAs in the field of applied linguistics based on Yang and Allison's (2003) framework 
through the use of the AntMover software. The findings showed that move Background information occurred in $100 \%$ of the corpus and that makes it an obligatory move in the discussion section of applied linguistics RAs. In another study which also targeted RAs from the field of applied linguistics, Dujsik (2015) examined 50 discussions using Peacock's (2002) framework of rhetorical moves. The findings showed that move Information occurred in $98 \%$ of the total corpus which is also considered as a frequent employed move by applied linguistics research writers. This move was used mostly to restate research aims. For instance, words or phrases that were seen to be associated with this move are set out, goal, and research questions. In the same line, Dobakhti (2016) analysed the discussion section from 15 qualitative RAs based on Swales's (1990) framework. Results from the study showed that move Providing information occurred in four RAs (30\%) and was used to provide readers with information. It was either used to provide background information (e.g. aim of the study) or present preview information (what is coming next). The writers provided background information (e.g. restated the aim of the study) either in the starting part of the discussion or at the ending part of it before summarizing their findings. From the above study, it can be concluded that research writers in the field of applied linguistics prefer to give some background information when they discuss their results in the discussion section.

Examining another discipline, Basturkmen (2012) studied the rhetorical moves in the discussion of dentistry RAs. The study involved not only moves but also steps and sub-steps. It adopted a framework proposed by Basturkmen (2009) based on RAs from the field of applied linguistics. The results showed that the discussion sections in Dentistry generally opened with move Background information (Move 1), unlike social sciences which generally open with statements of results (Holmes, 1997). Move 1 occurred in $60 \%$ of the corpus which makes it a conventional move. Research writers used this move to remind the readers of the purpose of the study or its key methodological features (Ex1).

Ex1: "This study aimed to clarify the clinical features of the..., evaluate the different diagnostic methods, and to evaluate the benefits of..." (Basturkmen, 2012: p. 140)

Investigating the field of psychology, Moyetta (2016) examined a corpus of 20 RAs from prestigious journals within the field. Results had shown that move Providing background information was an obligatory move. This finding is similar to the results from applied linguistics discipline (e.g., Dobakhti, 2016; Dujsik, 2015; Hashemi \& Moghaddam, 2016). Move Providing background information is considered as a central component in the discussion section within the psychology discipline (Moyetta, 2016). This move was used to strengthen the discussion by recapitulating main points, highlighting theoretical information, or reminding the reader of technical information (Swales, 1990). It was usually found as the opening move (Ex2), but it also appeared in different parts of the discussion as in Dobakhti (2016). 
Ex2: "The purpose of this research was to examine the effect of..." (Moyetta, 2016: p. 95)

In another study, Amnuai (2017) analysed the discussion section from 20 RAs in the field of accounting. The rhetorical structure of the discussion section was examined using Yang and Allison's (2003) model of moves. It was found that move Background information occurred in 13 (65\%) RAs. The linguistic devices that were viewed to be associated with this move are the phrase this paper, the verb report, and the use of present tense.

Ex3: "This paper reports the results of a study designed to provide additional evidence on individuals' compensation contract choices" (Amnuai, 2017: p. 4)

Unlike the aforementioned studies who examined all the rhetorical moves in RAs discussion, Joseph and Lim (2018) carried out a study that specifically examined move Background information in the discussion section of forestry RAs. They found that this move was signaled by the employment of purpose related lexemes, such as goal and objective, and procedural verbs, such as examine and investigate. Despite of their unique findings, Joseph and Lim (2018) recommended further studies on move Background information as the occurrences of this move witnessed variations across disciplines (e.g., dentistry, law, biochemistry). Therefore, the current paper seeks to conduct a deep analysis on move Background information in the discussion section of medical RAs.

\section{The Corpus}

The corpus of the current study involved the discussion section of 50 Medical RAs. According to the literature, the corpus size is considered sufficient to meet the objectives of the present research. In this, a small corpus enables some analyses such as moves/steps analysis and linguistic cues that require the hand coding of moves which otherwise may not be managed within a large corpus. Moreover, Fuertes-Olivera (2015) and Yang et al. (2015) argued that since the selected corpus are all from the same genre and discipline, sufficient data can be generated for the purpose of analysis regardless of their size.

There are several criteria that were taken into consideration when selecting the corpus of this research. The articles constructed from 5 medical journals which were among the top high-ranked in the field. These journals were also recommended by a head of the department, who is a professor in the field of medicine at the Faculty of Medicine, Universiti Malaya. The researcher made sure that only high cited RAs were taken into considered. It is worth mentioning that the high citation does not reflect the quality of the language used in the article. However, it shows the popularity of the research in the field which makes it more reliable. A total of 10 RAs were chosen from the following journals: New England Journal of Medicine, The Lancet, The Journal of the American Medical Association, British Medical Journal, Journal of Clinical Investigation. The RAs written by the same authors were not included. This is because more than one research article written by the same author may increase the chances of expe- 
riencing the use of similar language, structure, and style of writing, and that would be biased. Also, "nativeness" was ignored as a selection criterion. Since these articles had already been published by the respective journals, their authors were assumed proficient users of academic English conforming to the norms regardless of their first language and cultural background. In addition, all selected RAs must have a stand-alone discussion section that must be separated from finding and conclusion sections because the focus of this research is on the discussion section alone. After applying the aforementioned criteria, the corpus were compiled into one Word file and prepared for the analysis.

\section{Analytical Procedure}

Three stages were involved in the analysis; identifying move Background information, analysing the linguistic realisations and examining the sentence initial lexical bundles associated with this particular move. The researcher downloaded the medical corpus from the database of the journals selected in PDF format. After obtaining the required corpus, every text/discussion was assigned with a number (e.g., txt1, txt2, txt3). Then, the saved files were run into AntFileConverter software to be converted into ${ }^{*}$ txt format. In the following step, the total word-number in each discussion was counted by copy and pasting the discussion section from any file type to a Microsoft Word. According to Holmes (1997), "the sentence was considered the unit of analysis implemented for examining moves, and the identifying feature was the linguistic realisations that were seen to realise the communicative functions of each move." (p. 5). The hand-coding strategy was used despite the availability of some automated tools for conducting the linguistic analysis. This strategy was also done by recent studies (e.g., Ansarifar et al., 2018; Lubis, 2019) as it generated more fine-grained results. Therefore, the analysis was done manually by examining the discussion section sentences. After the analysis, the frequency and percentage were tabulated and included in the findings.

This process helped to verify the extent to which move Background information has been employed. This study considered $60 \%$ as the cut-off rate of move essentiality (Kanoksilapatham, 2005; Pho, 2008). In this, it will be decided that the move can be considered as obligatory (if the move will be detected in $100 \%$ of the discussion chapters), conventional (if it is detected in $60 \%$ to $99 \%$ of the discussion chapters), and optional (if it is in less than $60 \%$ of the discussion chapters). Once the move analysis of the samples has been completed, these samples are further analysed for their use of linguistic realisation and lexical bundles.

Regarding the linguistic realisations, several linguistic features such as grammatical subjects, tenses and hedges were observed, in works of literature (e.g., Kanoksilapatham, 2005; Pho, 2008) to have the potential of identifying and distinguishing rhetorical moves. Initially, the present research considered the linguistic features identified in previous studies (Alamri, 2017; Doró, 2013; Hyland, 2005; Kanoksilapatham, 2005; Nwogu, 1997; Pho, 2008; Vassileva, 2001). The list 
of features assessed in this present study are as follows: grammatical subjects, verb tenses, procedural verbs, and other explicit academic lexemes.

Grammatical subjects that were used as linguistic features for identifying moves by Pho (2008) were based on the classification proposed by MacDonald (1992). Grammatical subjects could have various forms of self-reference and self-mention occurring in the inclusion of words that referred to the author(s) of the paper, such as I, we, the author (s), and the researcher $(s)$. Meanwhile, other-reference included the specific names of other researchers or citations. In other words, the reference to the writers' own work occurred when referring to the study or paper. The verb tense and voice included three broad tenses and two voices in English. The tenses were in the past, simple, and future, whereas the voices were in active and passive forms, thus considered to be the grammatical aspects of linguistics realisations. Other linguistic devices considered in this research include procedural verbs. Procedural verbs, such as use and examine, could be employed to restate certain methodological aspects.

The researcher also considered looking at other explicit academic lexemes during the analysis that may enable the identification of some moves or steps in the discussion section of MRAs. Nwogu (1997) was the first to introduce the phrase "explicit lexemes" (p. 5) which refers to particular linguistic clues. Later, they were considered by Fryer (2007) in his move identification. Explicit lexemes could be verbs, nouns or any parts of speech (Davis, 2015) that signal explicitly the information contained in a move/step (Nwogu, 1997). In other words, they are academic vocabularies; their meaning reflects the name and/or the function of a move/step. For instance, the lexemes limit and limitation realise the function of step Indication Research Limitation (Jalilifar et al., 2012).

After the analysis of the rhetorical move and linguistic realisations were done, the researcher prepared the data for the analysis of LBs by the AntConc3.5.7w computer program commenced. To meet the requirement of the software, the Word files were saved in Plain Text format $\left(^{*}\right.$.text file). This was done via AntFileConverter software. Only then, the LBs in the texts were analysed and identified by an automated corpus tool based on three criteria: the cut-off frequency which is 40 cases per million words (Biber et al., 2004), the frequency of LBs which is in at least 5 different samples (Biber \& Barbieri, 2007; Cortes, 2004), and the length of word combinations which is 3 to 5 words lexical bundles. Finally, a list of lexical bundles was created.

The LBs were identified by searching for the co-occurrences of the linguistic realisation of the moves. For example, the procedural verb examine, which is one of the linguistic devices investigated in this study was typed in the software to look for words that co-occur with this verb to form a bundle. Examples of LBs identified by examining this verb are we examined that, and this study examined that.

\section{Results and Discussion}

Move Background information has appeared in 34 (64\%) of the corpus. Based 
on Kanoksilapatham's (2005) cut-off rate, this move is considered conventional. This move has yet to be reported in past studies (e.g., Davis, 2015; Fryer, 2012; Huang, 2014) on rhetorical moves of MRAs. These studies have only reported that the discussion section is usually written when reporting the main findings. However, in a recent published work, Arsyad et al. (2020a) have found this move as an optional in the discussion of MRAs that are published in an Indonesian journal. One likely reason behind the emergent of this move in a recent published RAs corpus is that the genre of research articles may change over time (Bhatia, 2004; Hyland, 2011). Li and Ge (2009) have also found that some moves would change from optional to obligatory and vice versa. As Paltridge (2013) has stated, the "communicative purpose of a genre ... may evolve over time, whereby it may change, expand, or shrink" (p. 348).

The communicative function in move Background information intends to provide introductory information about the research, which involves the primary purpose of research and the methods that are followed in the study. A research writer may remind the readers about the sample size and data analysis procedure of the study through this move. According to Amnuai (2017), this move is used by writers to prepare readers for the discussion of the results. The most frequent function of this move is to describe the research method, which has occurred in 30 (out of 50) discussions. Research writers may provide information regarding the sample size, tools, analytical procedure and classification scheme in describing the research method. Table 1 demonstrates the first function of this move and the linguistic features that are used to realise the function.

The first function (Describing the Research Method) is realised by the use of procedural verbs, with an occurrence of 25 times, followed by first-person plural pronoun (25 times) and simple past tense (24 times). The two most frequently used procedural verbs have been used and chose with an occurrence of 7 and 3 times, respectively. The use of procedural verbs is considered to describe the related aspects in previous studies (e.g., Joseph \& Lim, 2018; Khansari, 2016). Besides, the use of the first-person plural pronoun, we, has been observed to be a dominant subject in most cases where the move is written in the active voice. This first-person plural pronoun we occurred 17 times as a sentence subject and co-occurred with the procedural verbs to realise the first function. The following examples demonstrate the employment of these linguistics features.

Ex4: "In this study, we used the internationally accepted criteria to define post transplantation diabetes."

Ex5: "We used an ICD-10-CM based classification scheme that was not adapted from that of Fleming-Dutra et al., focused on a younger population, and used more recent data."

Ex6: "We chose this approach to enable a more robust evaluation of the incidence, as well to assess clinician recognition of ARDS."

Ex7: "We studied a large UK based community volunteer sample aged 40 to 70 at baseline, with a mean seven-year follow-up." 
Table 1. The function and the frequency of linguistic features of move background information.

\begin{tabular}{cc} 
Move Background information & \\
Function 1: Describing the research method & \\
Linguistic realisations $f$ & 25 \\
1. Procedural verbs & 7 \\
Use & 3 \\
Choose & 2 \\
Compare & 2 \\
Perform & 2 \\
Design & 9 \\
Others (i.e., conduct, select, compile) & 25 \\
2. First-person plural pronoun & 17 \\
We & 8 \\
Our & 24 \\
3. Simple past tense & 21 \\
Active voice & 3 \\
Passive voice & 24 \\
\hline
\end{tabular}

As shown in the examples, the procedural verbs have been written in the active form of simple past tense. The simple past tense is found to be the dominant tense (24 times) used to demonstrate the functions of move Background information. Writing the procedural verbs in the past tense also suggests that the research procedures have been completed, whereby these procedures are restated to enlighten readers about the methods in achieving the findings (Joseph \& Lim, 2018). The frequent occurrence of the pronoun we can also indicate the preference of the research writers to have a voice and claim ownership to the research explicitly. One of the reasons for the high usage of we could also be to include and engage the readers and the related disciplines (Li \& Ge, 2009). This reason could help shorten the distance between researchers and readers by initiating camaraderie with the readers (Amnuai \& Wannaruk, 2012). On the other hand, the passive voice is only noticed 3 times, which shapes the first function of this move (Example 8).

Ex8: "The sample size calculation was based on an intracluster correlation coefficient of 0.37 from a previous pilot study."

The dominant use of the active voice is further explained by Thomas and Hawes (1994) who state that the pattern "subject + verb + complement" is a frequent pattern with sentences that carry a procedural verb (p. 13). The focus in the use of active voice, however, would be on the agent (Davis, 2015), which in this case of RAs, is the researcher. However, Joseph and Lim (2018) have found 
the passive voice to be more dominant in describing research methods in this move of the discussion section. This contradictory result could be due to the disciplinary variation, whereby research writers from the field of forestry may prefer to use passive voice. At the same time, authors in the selected medical science RAs tend to demonstrate a voice explicitly in the research through the employment of first-person plural pronouns to claim ownership of the findings (Li \& Ge, 2009).

In a few cases where the procedural verb is not employed, medical writers are found to use the following verbs: to be (3), to do (1) and have (1). These verbs have the potential to occur in any part of the research but are not associated with specific moves or steps in the discussion section (Example $9 \& 10$ ). There is only one case, nonetheless, that the tense being used is the present perfect instead of past (Example 11). This single case of exception has also been reported by Amnuai (2019) who has found the present perfect tense to appear only once to introduce move Background information. The occasional use of present perfect tense in this move suggests that some research writers have their own preferable pattern.

Ex9: "In our study, we had to screen many more individuals to identify eligible and willing participants."

Ex10: "Our study was randomised and based on high quality baseline imaging."

Ex11: "We have performed the first randomised clinical trial evaluating the efficacy of ..."

Additionally, the possessive pronoun our is also employed frequently to express the function of describing the research method. The possessive form, our, has occurred 8 times in this function (Example $12 \& 13$ ), which based on the examples, is employed by the research writers as a strategy in claiming ownership of their work (e.g., our study, our paper), followed by the procedural verb designed to realise the move. However, when plural pronouns are not employed, research writers refer to their work through the employment of phrases such as this study (4), the study (2), the present study (1), and this cluster study (1). These are self-referential phrases, which are used to refer to the paper itself (Example 14). These phrases are also used as a strategy to claim the ownership of their work research and to distinguish from other studies (Amirian et al., 2008).

Ex12: "Our study was designed to determine whether adding bevacizumab to the first-line treatment for ..."

Ex13: "Our study was designed as a response to their call to (broken) arms in order to address this critical knowledge gap."

Ex14: "This study was based on births in 1988, before the introduction of antenatal steroids and surfactant, which ..."

The second function (Restating the Research Purpose) is employed by research writers to remind readers of the main focus or the main objective of the research. Readers would be aware of the primary purpose of the research as they read the RA and relate the findings of the research to the objectives. A similar 
function has also been reported by Amirian et al. (2008), who believe that by restating the purpose of the research, the readers would be reminded of the research aims. Table 2 shows the second function of move Background information and the related linguistic devices.

Similar to the first function, the function of Restating the Research Purpose is characterised by the employment of procedural verbs, which have occurred 7 times, the first-person plural pronouns, which have occurred 6 times and simple past tense, which has occurred 7 times. Amirian et al. (2008) has also reported that verbs, such as examine and aim, are dominant in the move on Statement of Aims. This similarity proves that procedural verbs are devices that are typically used to realise the background information related to the specific moves. In the present study, the most frequently used verb is examine, which has been detected 4 times to achieve this function. The following examples demonstrate the use of the procedural verb, examine, in achieving the second function.

Ex15: "Our study examined a much larger set of metastatic CRPC samples that were collected from distant organs through the warm autopsy program."

Ex16: "This 12-week trial examined the safety, tolerability, and LDLC-lowering efficacy of ..."

Past tense is employed on the verb, examine, to remind readers of the main purpose of the research, as well as to prepare readers for the results and the relevant interpretations. On the other hand, Example 16 is the only case whereby the subject of the sentence is not a first-person plural pronoun. Instead, the writer begins the sentence with the phrase this 12-week trial, which is a self-reference

Table 2. The function and the frequency of linguistic features of move background information.

Move Background information

Function 2: Restating the research purpose

Linguistic realisations $f$

1. Procedural verbs

Examine

Aim

Test

Sought

2. First-person plural pronoun

Our 
to the writers' work. The sentences that carry this function in the rest of the cases begin with the pronoun, we (Example 17), or the possessive, our (Example $15)$.

Ex17: "We tested the hypothesis that ..."

In total, 28 occurrences of first-person plural pronoun and the possessive case have been employed to achieve this move. The high frequency of first-person plural pronoun could be due to the contributors in recent years using more active voice than passive voice in academic writing ( $\mathrm{Li} \& \mathrm{Ge}, 2009$ ). This circumstance is most likely for research writers to project their voice and own the contributions of their study (Al-Shujairi, 2020). On the other hand, the simple past tense is employed at a total of 34 times. Simple past is observed to be the dominant tense used in this move, whereby 30 times of the occurrences have been active, and only 4 times were passive. The use of the past tense in this move can be rationalised by the positioning and the nature of the discussion section. The research has already been conducted, and therefore, the discussion is written based on the available results. Thus, the employment of the past tense is suitable for not only the research writers to express opinions but also for the readers to understand the discussion. This finding is, however, in contrast with findings from Amnuai (2017), who has shown that present simple tense is the most common in the discussion section of RAs within the field of accounting. The contradicted finding may be a result of the disciplinary variations. According to $\mathrm{Li} \& \mathrm{Ge}$ (2009), past tense is generally the most dominant tense (65.72\%) in the writing of MRAs.

Concerning the results of lexical bundles in the move Background information of the discussion section, LBs with 3 to 5 words are found (Table 3). They are employed to realise this move. The occurrence of most of these bundles is twice in the corpus except for one bundle our study was, which has occurred 3 times in this move.

Table 3. List of lexical bundles in move background information.

\begin{tabular}{cl}
\hline 1. 3-word LBs & $f$ \\
Our study was & 3 \\
2. 4-word LBs & $f$ \\
We studied a large & 2 \\
We tested the hypothesis & 2 \\
We used a classification & 2 \\
The present study combined & 2 \\
3. 5-word LBs & $f$ \\
This study was done in & 2 \\
This study was based on & 2 \\
The current study was to & 2 \\
\hline
\end{tabular}


The finding of LBs in this move within this present research is unique because these LBs have not been reported in previous studies (e.g., Abdollahpour \& Gholami, 2019; Jalali \& Moini, 2018; Mbodj-Diop, 2016) that have examined LBs in medical research writing. The reason for this new finding could be due to the emerging of this new move (Background information) in the analysis of the present corpus. Thus, the finding on the 4 - and 5-word bundles in the present study is as unique as the finding of move Background information in the discussion section of the selected MRAs. On the other hand, the finding of the 3-word bundle is in line with several previous studies. For instance, Jalali et al. (2014) have found that the bundle our study was is commonly employed in the introduction section by medical research writers. Further examples below are taken from the corpus analysed in this study to show the employment of some LBs in move Background information within the discussion section of MRAs.

Ex18: "Our study was randomised and based on high-quality baseline imaging ...”

Ex19: "We studied a large UK based community volunteer sample ..."

The 5-word LBs, which commonly consist of three bundles; this study was based on, the current study was to, and this study was done in, have also been detected in this research. These bundles are not reported in any recent work (e.g., Cortes, 2013; Jalali \& Moini, 2018; Li et al., 2020). Unlike 3 and 4 words strings, 5-word bundles end with a preposition (on, to, in). Besides, the 5-word bundles initiate the sentences and function as a trigger in achieving the meaning of the move (Example 20), which is similar to the LBs with 3 to 4 words. The finding of the 4- to 5-word strings in move Background information also shows a strong bundle move connection.

Ex20: "This study was done in an immunological low-risk patient population to compare the efficacy of ...".

\section{Conclusion}

The analyses of move Background information and its linguistic realisations including lexical bundles were beneficial for international graduate students, novice writers, and non-native English writers in academic writing. For example, the analysis of the first move in the discussion section of medical RAs in the present study appeared to provide insights into how research writers in the field should start their discussion of results and what kind of information to be included.

In this vein, the exploration of linguistic realisations, such as tenses, self-mentions, and procedural verbs, could benefit medical research authors in constructing the first communicative function of the discussion section. For instance, authors could acknowledge the employment of devices, such as self-mentions and procedural verbs to provide background information at the beginning of the discussion. The use of present tense is also common to prepare the reader for the discussion of the results. In short, the examination of these linguistic realisations 
would assist medical research authors to construct this particular communicative function of the discussion section.

Regarding formulaic language as a specific type of linguistic realisations, the list of lexical bundles identified in the present study would benefit ESP or EAP practitioners and course designers. However, it was important to deal with these bundles with caution, as Hyland (2008) reported that bundles occurred and behaved in dissimilar ways, depending on the disciplinary environment. As such, the structural classification of the lexical bundles could serve as the basis for task productions (Familiarisation with form and structure) designed to foster the retrieval and use of specific bundle types in performing specific rhetorical functions (Hyland, 2008; Mbodj-Diop, 2016; Neely \& Cortes, 2009). With the exposure to large numbers of lexical bundles frequently employed in academic writing, these tasks would help learners in effective and professional writing.

The clarification of move Background information and the list of lexical bundles associated with it would help postgraduates and novice writers in the field of medicine to write effective, well-structured, and well-written discussions of research findings. Rather than being confused about which expression or phrase to use in realising move Background information in the discussion, medical research authors can now refer to the list of lexical bundles when structuring this move and contribute to the readability of the research. For example, one may use the 5-word LB "This study was based on" to start the discussion by providing a background about the research methodology. It is important to mention that well-structured research would be easily comprehended by the audience, particularly journals editors and manuscript reviewers with the final say in accepting or rejecting a submitted manuscript.

\section{Conflicts of Interest}

The authors declare no conflicts of interest regarding the publication of this paper.

\section{References}

Abdollahpour, Z., \& Gholami, J. (2019). Embodiment of Rhetorical Moves in Lexical Bundles in Abstracts of the Medical Sciences. Southern African Linguistics and Applied Language Studies, 37, 339-360.

Alamri, B. M. (2017). Connecting Genre-Based and Corpus-Driven Approaches in Research Articles: A Comparative Study of Moves and Lexical Bundles in Saudi and International Journals. Doctoral Dissertation, University of New Mexico. http://digitalrepository.unm.edu/educlls_etds/81

Al-Shujairi, Y. B. (2020). What, Which and Where: Examining self-Mention Markers in ISI and Iraqi Local Research Articles in Applied Linguistics. Asian Englishes, 22, 20-34.

Al-Shujairi, Y. B. J., Tan, H., Abdullah, A. N., Nimehchisalem, V., \& Imm, L. G. (2019). Moving in the Right Direction in the Discussion Section of Research Articles. Journal of Language and Communication (JLC), 6, 459-473.

Amirian, Z., Kassaian, Z., \& Tavakoli, M. (2008). Genre Analysis: An Investigation of the Discussion Sections of Applied Linguistics Research Articles. The Asian ESP Journal, 4, 
39-63.

Amnuai, W. (2017). The Textual Organization of the Discussion Sections of Accounting Research Articles. Kasetsart Journal of Social Sciences, 40, 389-394. https://doi.org/10.1016/j.kjss.2017.10.007

Amnuai, W. (2019). Analyses of Rhetorical Moves and Linguistic Realizations in Accounting Research Article Abstracts Published in International and Thai-Based Journals. SAGE Open, 9, 1-9. https://doi.org/10.1177/2158244018822384

Amnuai, W., \& Wannaruk, A. (2012). Investigating Move Structure of English Applied Linguistics Research Article Discussions Published in International and Thai Journals. English Language Teaching, 6, 1-13.

Ansarifar, A., Shahriari, H., \& Pishghadam, R. (2018). Phrasal Complexity in Academic Writing: A Comparison of Abstracts Written by Graduate Students and Expert Writers in Applied Linguistics. Journal of English for Academic Purposes, 31, 58-71. https://doi.org/10.1016/j.jeap.2017.12.008

Arsyad, S., Purwo, B. K., \& Adnan, Z. (2020a). The Argument Style in Research Article Discussions to Support Research Findings in Language Studies. Studies in English Language and Education, 7, 290-307. https://doi.org/10.24815/siele.v7i2.16626

Arsyad, S., Zaim, M., Ramadhan, S., \& Lubis, A. A. (2020b). The Argument Style of Research Article Discussions by Non-Native Authors of English Published in International Journals. Journal of Applied Linguistics \& Literature (JOALL), 5, 193-212.

Basturkmen, H. (2009). Commenting on Results in Published Research Articles and Masters Dissertations in Language Teaching. Journal of English for Academic Purposes, 8, 241-251. https://doi.org/10.1016/j.jeap.2009.07.001

Basturkmen, H. (2012). A Genre-Based Investigation of Discussion Sections of Research Articles in Dentistry and Disciplinary Variation. Journal of English for Academic Purposes, 11, 134-144. https://doi.org/10.1016/j.jeap.2011.10.004

Bhatia, V. (2004). Worlds of Written Discourse: A Genre-Based View. London: A\&C Black.

Biber, D., \& Barbieri, F. (2007). Lexical Bundles in University Spoken and Written Registers. English for Specific Purposes, 26, 263-286. https://doi.org/10.1016/j.esp.2006.08.003

Biber, D., Conrad, S., \& Cortes, V. (2004). If You Look at ...: Lexical Bundles in University Teaching and Textbooks. Applied Linguistics, 25, 371-405. https://doi.org/10.1093/applin/25.3.371

Cortes, V. (2004). Lexical Bundles in Published and Student Disciplinary Writing: Examples from History and Biology. English for Specific Purposes, 23, 397-423. https://doi.org/10.1016/j.esp.2003.12.001

Cortes, V. (2013). The Purpose of This Study Is to: Connecting Lexical Bundles and Moves in Research Article Introductions. Journal of English for Academic Purposes, 12, 33-43. https://doi.org/10.1016/j.jeap.2012.11.002

Davis, R. H. (2015). A Genre Analysis of Medical Research Articles. Doctoral Dissertation, University of Glasgow. http://theses.gla.ac.uk/6724/

Dobakhti, L. (2016). A Genre Analysis of Discussion Sections of Qualitative Research Articles in Applied Linguistics. Theory and Practice in Language Studies, 6, 1383-1389. https://doi.org/10.17507/tpls.0607.08

Doró, K. (2013). Selling Their Research: The Linguistic Realization of Rhetoric Moves in English Thesis Abstracts Written by Hungarian Undergraduates. Romanian Journal of English Studies, 10, 181-191. https://doi.org/10.2478/rjes-2013-0016 
Dudley-Evans, T. (1994). Variations in the Discourse Patterns Favoured by Different Disciplines and Their Pedagogical Implications. In J. Flowerdew (Ed.), Academic Listening: Research Perspectives (pp. 146-158). Cambridge University Press. https://doi.org/10.1017/CBO9781139524612.012

Dujsik, D. (2015). A Genre Analysis of Research Article Discussions in Applied Linguistics.' Language Research 49, 453-477.

Fryer, D. L. (2007). Multidimensional Genre-Based Discourse Analysis of a Corpus of English-Language Medical Research Articles. Master Thesis, University of Oslo. https://www.duo.uio.no/bitstream/handle/10852/25523/2

Fryer, D. L. (2012). Analysis of the Generic Discourse Features of the English-Language Medical Research Article: A Systemic-Functional Approach. Functions of Language, 19, 5-37. https://doi.org/10.1075/fol.19.1.01fry

Fuertes-Olivera, P. A. (2015). Pedagogical Application of Specialized Corpora in ESP Teaching: The Case of the UVaSTECorpus. Scripta Manent, 3, 68-81.

Hashemi, M. R., \& Moghaddam, I. G. (2016). A Mixed Methods Genre Analysis of the Discussion Section of MMR Articles in Applied Linguistics. Journal of Mixed Methods Research, 13, 242-260. https://doi.org/10.1177/1558689816674626

Holmes, R. (1997). Genre Analysis, and the Social Sciences: An Investigation of the Structure of Research Article Discussion Sections in Three Disciplines. English for Specific Purposes, 16, 321-337. https://doi.org/10.1016/S0889-4906(96)00038-5

Hopkins, A., \& Dudley-Evans, T. (1988). A Genre-Based Investigation of the Discussion Sections in Articles and Dissertations. English for Specific Purposes, 7, 113-121. https://doi.org/10.1016/0889-4906(88)90029-4

Huang, D. (2014). Genre Analysis of Moves in Medical Research Articles. Stylus, 5, 7-17.

Hyland, K. (2005). Stance and Engagement: A Model of Interaction in Academic Discourse. Discourse Studies, 7, 173-192. https://doi.org/10.1177/1461445605050365

Hyland, K. (2008). As Can Be Seen: Lexical Bundles and Disciplinary Variation. English for Specific Purposes, 27, 4-21. https://doi.org/10.1016/j.esp.2007.06.001

Hyland, K. (2011). Looking though Corpora into Writing Practices. In V. Viana, S. Zyngier, \& G. Barnbrook (Eds.), Perspectives on Corpus Linguistics (pp. 99-114). Amsterdam: John Benjamins Publishing Company. https://doi.org/10.1075/scl.48.07hyl

Jalali, Z. S., \& Moini, M. R. (2018). A Corpus-Based Study of Lexical Bundles in Discussion Section of Medical Research Articles. Iranian Journal of Applied Language Studies, 10, 95-124.

Jalali, Z. S., Moini, M. R., \& Arani, M. A. (2014). Structural and Functional Analysis of Lexical Bundles in Medical Research Articles: A Corpus-Based Study. International Journal of Information Science and Management (IJISM), 13, 51-69.

Jalilifar, A., Hayati, A., \& Namdari, N. (2012). A Comparative Study of Research Article Discussion Sections of Local and International Applied Linguistic Journals. The Journal of Asia TEFL, 9, 1-29.

Jin, B. (2018). Rhetorical Differences in Research Article Discussion Sections of Highand Low-Impact Articles in the Field of Chemical Engineering. IEEE Transactions on Professional Communication, 61, 65-76. https://doi.org/10.1109/TPC.2017.2747358

Joseph, R., \& Lim, J. M. H. (2018). Background Information in the Discussion Sections of Forestry Journals: A Case Study. GEMA Online ${ }^{\circledast}$ Journal of Language Studies, 18, 198-216.

Kanoksilapatham, B. (2005). Rhetorical Structure of Biochemistry Research Articles. English for Specific Purposes, 24, 269-292. https://doi.org/10.1016/j.esp.2004.08.003 
Khansari, D. (2016). Comparison of Rhetorical Moves in Research Articles and Abstracts in Soft and Hard Disciplines. Doctoral Dissertation, Universiti Putra Malaysia. http://psasir.upm.edu.my/57980/

Li, L. J., \& Ge, G. C. (2009). Genre Analysis: Structural and Linguistic Evolution of the English-Medium Medical Research Article (1985-2004). English for Specific Purposes, 28, 93-104. https://doi.org/10.1016/j.esp.2008.12.004

Li, L., Franken, M., \& Wu, S. (2020). Bundle-Driven Move Analysis: Sentence Initial lexical Bundles in PhD Abstracts. English for Specific Purposes, 60, 85-97. https://doi.org/10.1016/j.esp.2020.04.006

Liu, Y., \& Buckingham, L. (2018). The Schematic Structure of Discussion Sections in Applied Linguistics and the Distribution of Metadiscourse Markers. Journal of English for Academic Purposes, 34, 97-109. https://doi.org/10.1016/j.jeap.2018.04.002

Lubis, A. H. (2019). The Argumentation Structure of Research Article Findings and Discussion Sections Written by Non-Native English Speaker Novice Writers: A Case of Indonesian Undergraduate Students. Asian Englishes, 22, 143-162.

https://doi.org/10.1080/13488678.2019.1669300

MacDonald, S. P. (1992). A Method for Analyzing Sentence-Level Differences in Disciplinary Knowledge Making. Written Communication, 9, 533-569.

https://doi.org/10.1177/0741088392009004004

Mbodj-Diop, N. B. (2016). Lexical Bundles in Medical Research Articles: Structures and Functions. Doctoral Dissertation, Michigan State University. http://libguides.lib.msu.edu/az.php

Moyetta, D. (2016). The Discussion Section of English and Spanish Research Articles in Psychology: A Contrastive Study. ESP Today-Journal of English for Specific Purposes at Tertiary Level, 4, 87-106.

Neely, E., \& Cortes, V. (2009). A Little Bit About: Analyzing and Teaching Lexical Bundles in Academic Lectures. Language Value, 1, 17-38.

Nodoushan, M. (2012). A Structural Move Analysis of Discussion Sub-Genre in Applied Linguistics. In International Conference on Languages, E-Learning and Romanian Studies (pp. 1-12). Lund University.

Nwogu, K. N. (1997). The Medical Research Paper: Structure and Functions. English for Specific Purposes, 16, 119-138. https://doi.org/10.1016/S0889-4906(97)85388-4

Paltridge, B. (2013). Genre and English for Specific Purposes. In B. Paltridge, \& S. Starfield (Eds.), The Handbook of English for Specific Purposes (pp. 347-366). Wiley-Blackwell.

Peacock, M. (2002). Communicative Moves in the Discussion Section of Research Articles. System, 30, 479-497. https://doi.org/10.1016/S0346-251X(02)00050-7

Pho, P. D. (2008). Research Article Abstracts in Applied Linguistics and Educational Technology: A Study of Linguitic Realizations of Rhetorical Structure and Authorial Stance. Discourse Studies, 10, 231-250. https://doi.org/10.1177/1461445607087010

Sadeghi, K., \& Alinasab, M. (2020). Academic Conflict in Applied Linguistics Research Article Discussions: The Case of Native and Non-Native Writers. English for Specific Purposes, 59, 17-28. https://doi.org/10.1016/j.esp.2020.03.001

Sheldon, E. (2013). The Research Article: A Rhetorical and Functional Comparison of Texts Created by Native and Non-Native English Writers and Native Spanish Writers. Doctoral Dissertation, University of New South Wales. http://unsworks.unsw.edu.au/

Swales, J. M. (1990). Genre Analysis: English in Academic and Research Settings. Cambridge University Press. 
Swales, J. M., \& Feak, C. B. (2004). Academic Writing for Graduate Students: Essential Tasks and Skills (2nd ed.). The University of Michigan Press.

Thomas, S., \& Hawes, T. P. (1994). Reporting Verbs in Medical Journal Articles. English for Specific Purposes, 13, 129-148. https://doi.org/10.1016/0889-4906(94)90012-4

Vassileva, I. (2001). Commitment and Detachment in English and Bulgarian Academic Writing. English for Specific Purposes, 20, 83-102. https://doi.org/10.1016/S0889-4906(99)00029-0

Yang, A., Zheng, S. Y., \& Ge, G. C. (2015). Epistemic Modality in English-Medium Medical Research Articles: A Systemic Functional Perspective. English for Specific Purposes, 38, 1-10. https://doi.org/10.1016/j.esp.2014.10.005

Yang, R. Y., \& Allison, D. (2003). Research Articles in Applied linguistics: Moving from Results to Conclusions. English for Specific Purposes, 22, 365-385.

https://doi.org/10.1016/S0889-4906(02)00026-1 